\title{
Memória e comunicação organizacional no Brasil: interfaces
}

Memory and organizational communication

in Brasil: interfaces

Memoria y comunicación organizacional

en Brasil: interfaces

- Doutora e mestre em Comunicação e Cultura pela Escola de Comunicação da Universidade Federal do Rio de Janeiro (ECO-UFRJ)

- Graduada em Jornalismo pela ECO-UFRJ

- Professora das graduações de Jornalismo e Publicidade da ESPM-Rio

- Pesquisadora dos seguintes grupos de pesquisa: "Coordenação interdisciplinar de estudos contemporâneos" (CIEC-UFRJ); "Comunicação e organizações" (ESPM-Rio); "Desafios da comunicação integrada nas organizações hoje"; "Estudos e pesquisas em comunicação organizacional" (UnB)

- Sócia-diretora da consultoria em comunicação organizacional Escrita Fina

- E-mail: lucia.santacruz@espm.br 


\section{Resumo}

Este artigo procura investigar as interfaces entre a cultura da memória e as ações de comunicação das organizações no cenário brasileiro. Apoiado nos resultados de recente pesquisa do estado da arte da temática no Brasil, 0 artigo se vale de duas iniciativas empresariais - o site Memória das Comunidades Natura e o Centro de Memória Bunge - para refletir sobre os usos que a comunicação organizacional faz da Memória das organizações para produzir discursos de construção de identidade e estabelecer relacionamentos com os públicos de interesse de empresas e instituições. 0 referencial teórico dos estudos de memória vem dos campos da história e da museologia.

\section{PALAVRAS CHAVE: MEMÓRIA ORGANIZACIONAL・COMUNICAÇÃO ORGANIZACIONAL・IDENTIDADE CORPORATIVA.}

\section{Abstract}

This article seeks to investigate the interfaces between the culture of memory and organizational communication actions in the Brazilian environment. Based on the results of a recent survey of the state of the art in Brazil, the article draws on two business initiatives - Memória das Comunidades Natura site and the Centro de Memória Bunge - to reflect on the uses that the memory of the organizations makes to produce discourses of construction of identity and establish relationships with the stakeholders of companies and institutions. The theoretical referential of the studies of memory comes from the fields of history and of museology.

\section{KEYWORDS: ORGANIZATIONAL MEMORY•ORGANIZATIONAL COMMUNICATION•CORPORATE IDENTITY.}

\section{Resumen}

En este artículo se pretende investigar las interfaces entre la cultura de la memoria y las acciones de comunicación de las organizaciones en el escenario brasilero. Con el apoyo de los resultados de una reciente investigación del estado del arte del tema en el Brasil, el artículo trabaja con dos iniciativas empresariales - el sitio Memória das Comunidades Natura y el Centro de Memória Bunge - para reflexionar sobre los usos que la comunicación organizacional hace de la memoria de las organizaciones para producir discursos de construcción de identidad y establecer relaciones con los públicos de interés de las empresas e instituciones. El sustento teórico de los estudios de la memoria viene de los campos de la historia y la museología. 

om o fim das utopias, explicitado na queda do muro de Berlim, em 1989, também ruíram alguns ícones da modernidade: a crença no futuro, a noção de progresso e de evolução das sociedades. 0 futuro se torna uma incógnita e não uma meta a ser alcançada, o que leva a um retorno ao passado como lugar de nutrição, capaz de jogar luzes sobre o presente. Instalada a crise do futuro, vivida numa espécie de ressaca dos sonhos, encontramos as ruínas do passado, mas não pela perspectiva da história, que jaz em fragmentos. A memória desponta como instrumento fundamental para a formação de identidades nacionais e individuais, ocupando um espaço antes destinado a outras narrativas, como ressalta Joël Candau (1998).

\section{A MEMÓRIA ENTRA EM CENA}

Os estudos da memória vêm ganhando consistência em diversas áreas das ciências sociais a partir dos anos 1980 (Huyssen, 2000), identificando uma cultura da memória, a qual implica uma dilatação do campo do memorável (Ribeiro; Barbosa, 2007), que se manifesta em uma multiplicação de práticas voltadas para o passado - a valorização do relato pessoal, da escrita de si, da biografia, de movimentos de moda retrô, objetos vintage, filmes de época. Empresas investem em reedição de embalagens históricas, montam ambientes de venda semelhantes a lojas antigas, fazem lançamentos por tempo limitado de produtos de outras épocas, transformando a nostalgia em um forte atributo de diferenciação mercadológica (Santa Cruz, 2013a).

0 crescente interesse pelo resgate do passado, na sua dimensão do vivido, encontra diversas explicações. Estas vão desde a aceleração da história, na concepção de Pierre Nora (1993), passando pela percepção de Candau (1998) de valorização da memória como compensação tanto pela aceleração do tempo quanto pela crise das identidades, até a visão de Huyssen. Para este último, o impulso memorialista também se instala como espetáculo e como objeto da sociedade do consumo, numa "comercialização em massa da nostalgia" (Huyssen, 2000, p. 89).

Esse cenário aponta para a formação de uma cultura da memória, em que o ato de relembrar é celebrado e prestigiado como fruto do vivido, do experimentado pessoalmente. A eclosão de discursos da memória pode ser verificada rapidamente ao se folhear um caderno de cultura de um jornal diário de uma grande capital brasileira ou ao assistir a um telejornal nacional. Invariavelmente haverá neles uma reportagem, nota, artigo ou coluna que trate de algum produto cultural cuja base seja a memória.

A ascensão da cultura da memória se expressa, ainda, em ações como a constituição de comissões da verdade, buscando entender o que aconteceu no passado recente de países sob ditadura militar. Mas também encontra eco nas empresas, que se apoiam na memória para construir uma identidade institucional como um ferramental de relacionamento com seus públicos de interesse. Os modos pelos quais os indivíduos percebem e se relacionam com as organizações, além de terem se tornado um tema central nos estudos organizacionais, despontam como pistas para que as organizações, elas mesmas, alimentem o pertencimento e a identidade, tanto a individual quanto a coletiva. As organizações contemporâneas se estruturam pelo compartilhamento dos mesmos valores, visão, missão e objetivos, reunindo pessoas diferentes, em uma espécie de camaradagem, forjando uma cultura (Santa Cruz, 2007).

A cultura da memória se consolida em "santuários da memória" ou "lugares de memória" (Nora,1993), criados especificamente para conservar uma memória, uma tradição, uma experiência vivida coletivamente, que podem ser tanto espaços físicos quanto produções abstratas e rituais. 
Os lugares de memória nascem e vivem do sentimento de que não existe memória espontânea, que é preciso criar arquivos, que é preciso manter os aniversários, organizar as celebrações, pronunciar as honras fúnebres, estabelecer contratos, porque estas operações não são naturais (...). Se vivêssemos verdadeiramente as lembranças que eles envolvem, eles seriam inúteis. $E$ se, em compensação, a história não se apoderasse deles para deformá-los, transformá-los, sová-los e petrificá-los, eles não se tornariam lugares de memória. É este vai-e-vem que os constitui: momentos de história arrancados do movimento de história, mas que the são devolvidos (Nora 1993, p. 13).

Essa noção de Nora reforça a compreensão de que a memória é um fenômeno construído socialmente, cujas funções essenciais são manter a coesão interna e defender os limites do que um grupo tem em comum (Pollak, 1989; 1992). Maurice Halbawchs (1990) assinala que essa memória coletiva se assenta sobre um sistema simbólico, através do qual ocorrem a identificação e o compartilhamento de significados.

Estudar esses movimentos de formação de lugares de memória por parte das organizações no Brasil, especialmente em sua interface com a comunicação organizacional, representa problematizar os usos que esses atores vêm fazendo das práticas memorialistas.

\section{PROBLEMATIZAÇÃO DO FENÔMENO}

Muito embora reconheça que outros campos do conhecimento vêm se debruçando sobre a questão da memória, notadamente a administração (através dos estudos organizacionais), a psicologia, a neurociência e a linguística, este artigo se baseia nos estudos de memória a partir da perspectiva da história e da museologia para investigar as interfaces entre a cultura da memória e as ações de comunicação das organizações no cenário brasileiro. Além desse referencial teórico, a análise se apoiará na produção nacional do campo da comunicação sobre a temática. Ainda que admitamos os riscos dessa limitação, entendemos também que todo recorte pressupõe o enquadramento e escolhas tanto metodológicas quanto conceituais. No caso, o que nos interessa é verificar o pensamento brasileiro comunicacional.

Apesar da emergência da temática da memória no ambiente das ciências sociais e nos estudos organizacionais, bem como do crescimento de projetos comunicacionais de cunho memorialístico ${ }^{1}$, menos de $1 \%$ dos artigos, teses, dissertações, monografias de especialização e paperscientíficos do campo da comunicação no Brasil tem como objeto de estudo a relação entre memória organizacional e comunicação organizacional. Esta é a principal conclusão de um estudo do tipo estado da arte sobre a temática, que desenvolvi ao longo de 2013 na ESPM-Rio.

Pesquisei 7.716 teses, dissertações de mestrado, artigos em periódicos e trabalhos apresentados em congressos da área acadêmica de comunicação no Brasil, no período de 1980 a 2013, e identifiquei um total de 71 produções científicas relacionando memória organizacional e comunicação organizacional (Santa Cruz, 2013b). 0 período foi escolhido por ser a partir de 1980 que a memória começou a ser um tema consistente nas ciências sociais, especialmente nos estudos de história e na museologia, e também por ter sido naquela década que a comunicação organizacional, segundo autores como Margarida Kunsch (1997) e Wilson Bueno (2003), iniciou sua consolidação no país.

1 A última estatística disponível indica que cerca de 20\% das quinhentas maiores empresas no Brasil produzem algum projeto na área de memória (Nassar, 2006). 
0 pequeno percentual de produção científica do campo da comunicação que estuda a memória organizacional em sua interface com a comunicação organizacional está fortemente concentrado no estado de São Paulo, com alguma participação também do Rio Grande do Sul, tendo como principais instituições produtoras a Escola de Comunicação e Artes da Universidade de São Paulo (ECA-USP) e a Faculdade de Comunicação Social da Pontifícia Universidade Católica do Rio Grande do Sul (Famecos/PUC-RS). A principal referência bibliográfica dessa produção científica é o professor da ECA-USP Paulo Nassar, autor também da única tese da área sobre essa temática, defendida em 2006 e que continua sendo a principal fonte conceitual na área. As demais influências são da área de história, sugerindo que essas pesquisas trabalham com uma concepção de memória baseada em perspectivas historiográficas² .

$\mathrm{Na}$ análise do material, identificamos que existem cinco grandes chaves conceituais presentes na produção acadêmica brasileira que relaciona memória e comunicação organizacional: 1) memória como estratégia de comunicação (utilizada como ferramenta de disseminação dos valores das organizações e como meio de ampliar o seu reconhecimento perante a sociedade); 2) memória como cultura organizacional (gestão de pessoas, desenvolvendo o senso de identificação e de pertencimento, por meio da transmissão de valores institucionais); 3) Memória como gestão do conhecimento (a função utilitária da memória no processo de preservação do conhecimento construído na organização, sua recuperação e seu compartilhamento); 4) Memória como trajetória institucional (o resgate da história de uma organização); 5) Memória como saber coletivo (num sentido que quase se aproxima do de cultura, como o conjunto de valores, crenças, símbolos e significados de uma coletividade).

A chave conceitual mais frequente é a que vê a memória como uma estratégia de comunicação, reforçando o enquadramento que a comunicação organizacional destina à memória organizacional - o de ferramenta, o que conduz a uma visão utilitária ainda que se pretenda estratégica. Este entendimento é reforçado pelo volume de textos que reforçam o papel do relaçõespúblicas no processo de memorialização das organizações. Praticamente todas as dissertações - e especialmente a tese de Nassar - pretendem delimitar a memória organizacional como um campo de atuação profissional.

Da mesma forma, o desempenho bem mais opaco das demais categorias parece indicar que a percepção do campo da comunicação organizacional é de se atribuir a responsabilidade à memória organizacional, sem esmiuçar aspectos como gestão do conhecimento, saber coletivo, trajetória institucional - pontos que estariam mais relacionados com a gestão das organizações.

Esse ponto talvez mereça alguma reflexão - e nem exatamente acadêmica, mas sim como campo de atuação profissional - se tomarmos por base o esforço contínuo da comunicação organizacional para ser percebida e valorizada como uma área de inteligência estratégica. Ao não considerar outros aspectos tão importantes da gestão, a área não se enfraquece enquanto estratégica?

Por outro lado, uma avaliação possível é depreender que as pesquisas evidenciam o enquadramento que a própria área da comunicação destina à memória organizacional - o de ferramenta, o que conduz a uma visão utilitária ainda que se pretenda estratégica.

2 Além de Nassar, encontramos a professora Margarida Kunsch, também da ECA-USP, as historiadoras brasileiras Beth Totini, Élida Gagete e Karen Worcman, os franceses Edgar Morin, Pierre Nora, Le Goff, Michael Pollak e Henri Bergson e o espanhol Manuel Castells. 
Fruto direto das transformações ocorridas no mundo do trabalho, a partir da adoção de novas tecnologias da informação e de alterações nos paradigmas de organização do processo produtivo, a comunicação desempenha um papel nevrálgico no ambiente corporativo atualmente. A revolução tecnológica concentrada nas tecnologias da informação remodela a base material da sociedade num ritmo acelerado (Castells, 2003). Essas mudanças levam à substituição do sistema fordista (baseado na produção em massa, na economia de escala, na rígida divisão de tarefas e funções e numa grande estrutura vertical) por uma estrutura de redes, dinâmica, flexível, desterritorializada, desnacionalizada e fortemente calcada no conhecimento e na inovação.

À medida que a comunicação se torna peça-chave, especialmente no ambiente dos relacionamentos públicos das empresas e instituições, cada vez mais seus gestores têm como desafio administrar a dimensão simbólica dos negócios, o imaginário de suas ações (Nassar, 2004).

Em outras palavras, uma organização precisa construir uma cultura da comunicação, que permeie suas práticas e funcione como elemento estruturante de suas relações. Uma estratégia que "assume uma força de mediação ou harmonização entre organização e ambiente, entre contextos interno e externo" (Cogo, 2006 p. 36).

Pressionada pelo mercado e pela sociedade ${ }^{3}$, a comunicação organizacional tem adotado novos objetivos, reposicionado valores e estratégias e consolidado sua atuação como esfera fundamental no processo de tomada de decisão nas organizações, um processo contemporâneo à ascensão da cultura da memória.

A memória organizacional é um aprendizado da organização capaz de ser transportado por "portadores de memória" (cultura, estrutura, sistemas e procedimentos) e armazenada em "elementos de memória" (por exemplo, visão de mundo, símbolos e sagas para a cultura, autoridade e grupos de projeto para a estrutura, indicadores de performance e regras e rotinas para procedimentos) (Santa Cruz, 2012 p. 11).

A força do uso da memória na comunicação da identidade organizacional reside na sua capacidade de transmitir não apenas o conceito da marca, mas também, como destaca Carolina da Cruz Costa (2006), elementos intangíveis como orgulho, tradição, valores e, claro, história. Além disso, o apelo memorialista envolve o aspecto emocional.

Recordar, em sua raiz etimológica, significa trazer de novo ao coração. Em projetos de registro da memória, se está diante de operações de resgate do afeto. 0 que, em outras palavras, representa ainda a recuperação do elemento humano e individual nas organizações: construção do passado a partir de emoções e vivências individuais e coletivas (Santa Cruz, 2012, p. 6).

\section{Projetos de memória organizacional}

Na concepção da Associação Brasileira de Comunicação Empresarial (Aberje), "a memória empresarial é ferramenta de suporte à gestão estratégica de comunicação e de relacionamento" (Aberje, 2012). Nessa abordagem, projetos de memória empresarial devem extrapolar o sentido de celebração ou da simples preservação dos registros do passado, "uma vez que podem agregar valor ao negócio e à marca institucional, servindo de suporte ao brand equity e à gestão do patrimônio informativo da organização" (Aberje, 2012).

3 Entre essas demandas da sociedade, podemos citar transparência às ações empresariais, condições de trabalho e remuneração justas, atenção ao meio ambiente e à sustentabilidade dos produtos, responsabilidade social, ética nos negócios etc. 
A formalização do conteúdo coletado num projeto de memória organizacional pode se traduzir em vários produtos: eventos, campanhas internas e externas, memória oral, museus empresariais, documentários, galeria dos presidentes, concurso de histórias, ações de marketing, hot-site, brindes, veículos de comunicação internos específicos do projeto memória, ações de assessoria de imprensa, publicações e exposições itinerantes. De modo geral, o estímulo para 0 desenvolvimento desse tipo de ação são as celebrações históricas, normalmente nas chamadas "datas redondas" - dez, cinquenta, cem anos de fundação da organização.

Um exemplo que se desprende dessa exigência de comemoração de calendário e reforça o caráter de formação de identidade de uma marca e/ou empresa são as narrativas da Memória das Comunidades Natura, no portal do Museu da Pessoa ${ }^{4}$.

Figura 1 - Site Memória das Comunidades Natura

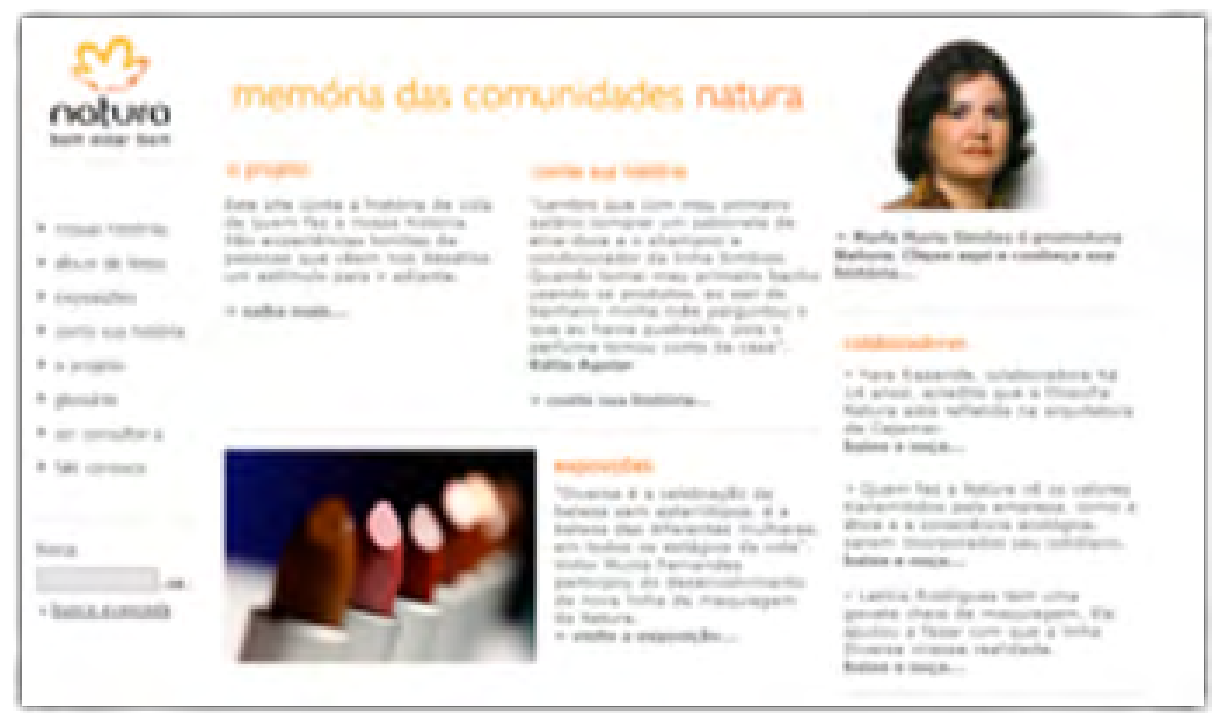

0 projeto nasceu com o objetivo de registrar, preservar e transformar em informação a história de vida das pessoas que fazem a história da empresa. Os depoimentos são de consultoras e consultores Natura, promotoras Natura, colaboradores, fornecedores e consumidores, porém o espaço está aberto para receber depoimentos de qualquer pessoa que se identifique com a empresa. "É dessa maneira que vamos formar uma grande rede de memória de indivíduos que fazem parte de nossa trajetória", afirma o texto introdutório no site, que utiliza a mesma identidade visual da Natura.

Para Silvia Dantas, que estudou a estratégia da fabricante de cosméticos, com a criação dessa comunidade, "a Natura dedica-se a uma construção conjunta da imagem da marca, ao mobilizar as esferas da memória e da subjetividade feminina, com o objetivo de atribuir valores e significados para a corporação" (Dantas, 2011). Essa iniciativa representa uma mudança no padrão organizacional tradicional, já que a empresa atribui voz ao outro para que fale por ela, enquanto as consultoras têm uma oportunidade de construir subjetividade na sua relação com a empresa. Em seu artigo, a pesquisadora investiga como as consultoras Natura incorporam o discurso da corporação e promovem construções simbólicas de sua identidade pessoal e da empresa por meio das suas histórias de vida.

Ao entrar em um ambiente midiático caracterizado pela coleta de histórias de vida, para expor as narrativas de sua equipe, a Natura cria uma estratégia diferenciada, que pode ser considerada publicização, termo muito empregado na atualidade para denominar as ações de marca que invadem todos os espaços, no momento em que fronteiras entre informação, entretenimento e publicidade são diluídas (Dantas, 2011, p. 1).

4 Museu da Pessoa é um museu virtual de histórias de vida, disponível em http://www.museudapessoa.net, aberto à participação gratuita de toda pessoa que queira compartilhar sua história a fim de democratizar e ampliar a participação dos indivíduos na construção da memória social. 
Nessa perspectiva, a concepção que emana da utilização que a Natura faz do projeto de memória envolvendo suas consultoras, a partir da classificação por nós proposta, é a de memória como cultura organizacional, uma vez que pretende desenvolver o senso de identificação de pertencimento. Ao mesmo tempo, esse conceito é trabalhado como estratégia de comunicação, já que procura fazer a vinculação da marca com a história de vida das consultoras, ampliando seu reconhecimento na sociedade. Trata-se, portanto, de uma ação do portfólio de comunicação integrada.

O foco atual da comunicação organizacional está na criação e manutenção dos relacionamentos. Walter Benjamin (1998), em seu artigo "O narrador", considera que a noção de narrativa está intrinsecamente relacionada à de experiência, do conhecimento obtido da prática, dos costumes, da construção cultural coletiva. Dessa forma, narrar seria partilhar. É muito própria de Benjamin a visão da narrativa como equivalente à ideia genérica de comunicação, ou seja, a ação de pôr em comum, de colocar em circulação, de promover a partilha discursiva das capacidades de compreender. George Lukács faz uma distinção entre narrar e descrever, em seu ensaio homônimo (apud Konder, 2001). A descrição é uma espécie de cumplicidade com o que existe, legitimando-o, fazendo crer que a realidade é e será sempre aquilo que ela está sendo no momento em que é descrita, já que ficam enfraquecidas a percepção e a representação do que está mudando, do processo pelo qual a realidade está sempre se tornando aquilo que ela ainda não é. A perspectiva do narrador, ao contrário, estimula a compreensão da realidade como um processo de transformação incessante, isto é, como um movimento que está permanentemente engendrando o novo.

Os projetos de memória organizacional, quando operacionalizados como ferramentas estratégicas de comunicação, atendem a estas duas acepções: ao ato de tornar comum, compartilhar; e ao processo de criação constante do novo a partir da tradição. Relembrar, assim, se torna também recriar e definir identidades coletivas e individuais. Ou, parafraseando Hobsbawn, o resgate da memória pode representar a invenção de tradições.

Projetos de memória organizacional concretizam a trajetória da instituição para seus diversos públicos de relacionamento, gerando conhecimento, ao mesmo tempo em que reforçam vínculos emocionais. As ações também colaboram para aumentar a autoestima dos empregados, que se sentem parte atuante da história e percebem a valorização da sua experiência pessoal na construção de uma experiência coletiva. Ao mesmo tempo, recuperar a memória fornece subsídios internos para planejamento de ações, formulação de objetivos e estratégicas. É uma fonte poderosa de recursos para nutrir a cultura da organização com elementos da sua própria história, contribuindo para a gestão de relacionamentos com todos os públicos.

\section{Centros de documentação e memória}

Na visão de Maria Elizabeth Totini [s. d.], o centro de documentação e memória (virtual e físico) é considerado o modelo ideal e mais completo para o projeto de memória organizacional, já que se trata de um espaço permanente, o que o torna constante e atuante, e não somente um produto específico de registro para marcar uma comemoração da organização. Segundo a historiadora, esses centros são

setores responsáveis pela definição e aplicação de uma política sistemática de resgate, avaliação, tratamento técnico e divulgação de acervos e, principalmente, pelos serviços de disseminação do conhecimento acumulado pela empresa e de fontes de interesse histórico (Totini, s. d.).

Um centro de memória se compõe basicamente de umaárea de memória técnica e outra memória institucional. A de memória técnica é encarregada da gestão de documentos e informações, enquanto a de memória institucional fica responsável pela pesquisa histórica e por produtos institucionais. 
0 Centro de Memória Bunge, criado em 1994, promove ações com diferentes públicos - interno, comunidade acadêmica, público em geral, assessoria de imprensa, estudantes e outras empresas, desempenhando atendimento a pesquisas, exposições temáticas, jornadas culturais, oficinas de preservação, visitas técnicas e integração de empregados. Em cada uma dessas atividades, está a reafirmação da identidade da empresa, reforçando vínculos emocionais entre a ela e seus públicos, fortalecendo a imagem e valorizando suas marcas, como é o caso na exposição virtual "Um Brasil de sabores", que apresenta as origens da cozinha brasileira e a influência dos imigrantes na composição da nossa alimentação.

Figura 2 - Exposição "Um Brasil de sabores" Centro de Memória Bunge.

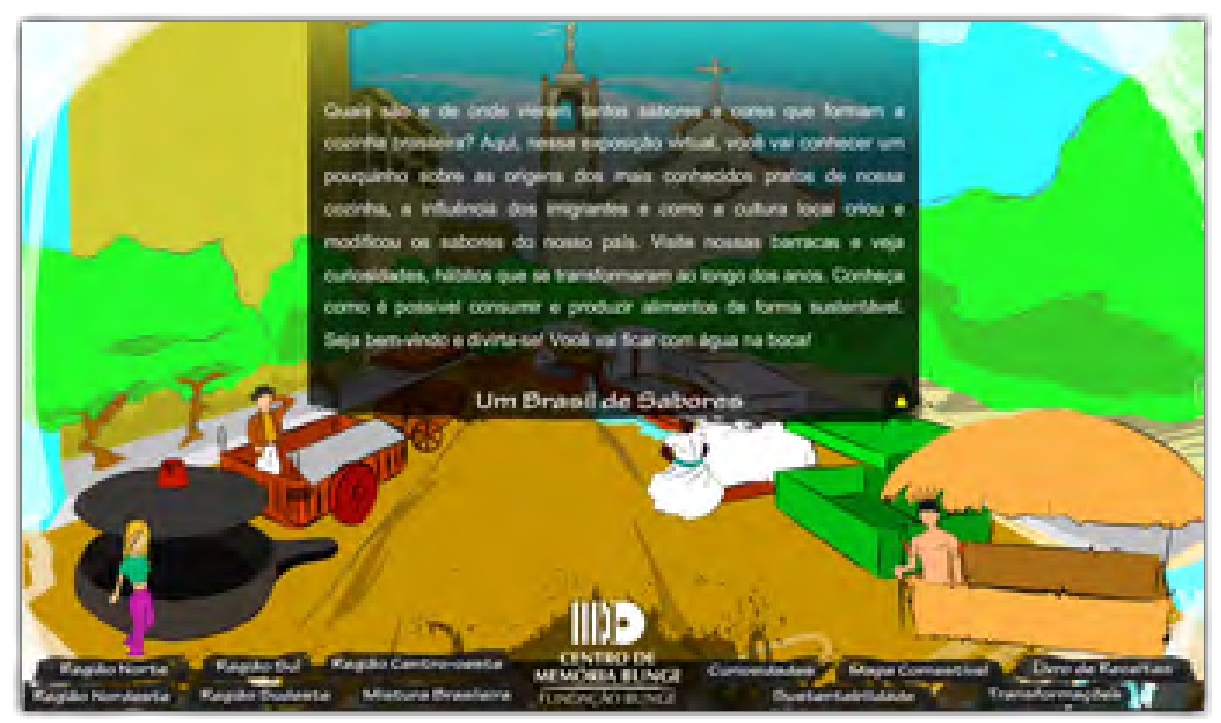

0 caso do Centro de Memória Bunge se inscreve numa perspectiva mais ampla da relação entre memória e comunicação organizacional. Continua sendo uma ferramenta estratégica de comunicação, mas também pode ser percebido como gestão do conhecimento, uma vez que contribui para a preservação e a difusão do conhecimento produzido na própria organização - uma exposição virtual mais recente apresenta o processo de produção de margarina, através das embalagens e propagandas dos produtos Bunge. E também assume características de memória como saber coletivo, pois destaca e organiza os elementos culturais de um grupo, reforçando identidades e simbolismos.

\section{CONSIDERAÇÕES FINAIS}

Este artigo procurou apresentar, através da análise de dois produtos midiáticos, como a comunicação organizacional brasileira vem utilizando a memória das instituições para produzir discursos de construção de identidade e estabelecer relacionamentos com os públicos de interesse de empresas e organizações.

0 desenvolvimento das diversas iniciativas memorialísticas no campo das organizações, além de implicar uma ampliação do mercado de atuação da comunicação corporativa, também aponta para itens que merecem ser analisados do ponto de vista acadêmico, colocados em perspectiva teórica e confrontados com outros enfoques. Trata-se de questões como: a revisitação do passado, o uso das experiências para criação de imagem institucional, a valorização dos sujeitos e suas vivências, a reconfiguração da identidade, a recuperação da nostalgia, o resgate da oralidade etc.

No siteMemória das Comunidades Natura, a fabricante de cosméticos se vale do depoimento pessoal de sua força de vendas, bem como de fornecedores e também de consumidores, para promover a construção da imagem da marca. A valorização do relato pessoal é o tom mais forte dessa iniciativa, que tanto objetiva desenvolver o senso de identificação e de pertencimento, 
estabelecendo uma cultura organizacional da qual participam todos os atores envolvidos, quanto pretende ampliar seu reconhecimento perante a sociedade, adotando a memória como uma estratégia de comunicação.

Já o Centro de Memória Bunge, além de ferramenta estratégica de comunicação, utiliza a memória como uma possibilidade de gestão do conhecimento produzido na instituição e também como produtora de um saber coletivo. Ao recuperar e consolidar elementos culturais de um grupo, especialmente através da alimentação, a iniciativa reforça identidades, associando-as à própria empresa.

A diferença entre as duas iniciativas está no emissor do discurso memorialístico. Enquanto na ação da Natura encontramos os relatos pessoais, no Centro de Memória Bunge temos um produto mais institucional, mais impessoal. Não se trata de fazer um julgamento ou uma hierarquização das duas ações, mas demarcar essa distinção é importante porque ressalta a apropriação da memória como um mecanismo produtor de sentidos.

Halbawchs (1990) nos recorda que memórias não podem ser consideradas reconstituições fiéis do passado, mas devem ser sempre percebidas como reconstruções: construções sociais, continuamente atualizadas e reconfiguradas.

Longe de significar ser este um assunto de pouca relevância, a baixa incidência de estudos no campo da comunicação no Brasil a respeito das práticas de memória organizacional indica que há um grande espaço para o desenvolvimento de novas pesquisas sobre o tema.

\section{REFERÊNCIAS}

ABERJE. Contexto de velocidade e ansiedade impulsiona projetos de história e memória. Aberje On-line, 22/11/2012. Disponível em: <http://www.aberje.com.br/acervo_not_ver.asp?ID_NOTICIA=7768>. Acesso em: 10 fev. 2013.

BENJAMIN, Walter. Illuminations: essays and reflections. [1969]. New York: Schoken Books, 1998.

BUENO, Wilson. Comunicação empresarial: teoria e pesquisa. Barueri, SP: Manole, 2003.

CANDAU, Joël. Memoire et identité. Paris: PUF, 1998.

CASTELLS, Manuel. A sociedade em rede. Rio de Janeiro: Paz e Terra, 2003.

COGO, Rodrigo S. Memória como recurso de comunicação organizacional: a atratividade do storytelling em tempos de atenção difusa: um estudo teórico. São Paulo, 2010.139f. Monografia (Especialização em Gestão Estratégica em Comunicação Organizacional e Relações Públicas) - Escola de Comunicações e Artes da Universidade de São Paulo, 2010.

COSTA, Carolina da Cruz. O resgate da memória empresarial e seus impactos na imagem da empresa: case Centro de Memória Bunge. São Paulo, 2006, 162 f. Monografia (Especialização em Gestão Estratégica em Comunicação Organizacional e Relações Públicas) - Escola de Comunicações e Artes da Universidade de São Paulo, 2006. 
DANTAS, Silvia. A publicização e as vozes das consultoras: a Memória das Comunidades Natura do Museu da Pessoa. In: ENCONTRO DOS GRUPOS DE PESQUISAS EM COMUNICAÇÃO, XI - evento componente do XXXIV Congresso Brasileiro de Ciências da Comunicação, Recife, PE, 2 a 6 de setembro de 2011. Anais... São Paulo: Intercom, 2011.

HALBAWCHS, Maurice. A memória coletiva. São Paulo: Vértice, 1990.

HOBSBAWN, Eric. A invenção das tradições. São Paulo: Saraiva, 2012.

HUYSSEN, Andreas. Seduzidos pela memória: arquitetura, monumentos, mídia. Rio de Janeiro: Aeroplano, 2000.

KONDER, Leandro. A narrativa em Lukács e em Benjamin. Revista Semear 7. Cátedra Padre António Vieira de Estudos Portugueses. PUC-Rio, 2001. Disponível em <http://www.letras.puc-rio.br/catedra/revista/7Sem_22.htm>. Acesso em: 09 nov. 2010

KUNSCH, Margarida Maria Krohling. Relações públicas e modernidade: novos paradigmas na comunicação organizacional. São Paulo: Summus,1997.

MEMÓRIA DAS COMUNIDADES NATURA. Disponível em:<http://www.museudapessoa.net/natura/> Acesso em: 05 maio 2014.

NASSAR, Paulo. Relações públicas e história empresarial no Brasil: estudo de uma nova abrangência para o campo das relações públicas. Tese (Doutorado em Ciências da Comunicação) - ECA-USP, São Paulo, 2006.

(Org.). Memória de empresa: história e comunicação de mãos dadas, a construir o futuro das organizações. São Paulo: Aberje, 2004.

NORA, Pierre. Entre memória e história: a problemática dos lugares. Trad. De Yara Khoury. Projeto História, São Paulo-Revista do Programa de Estudos Pós-Graduados em História e do Departamento de História da PUC-SP, n. 10, p.7-28, dez. 1993.

POLLAK, Michael. Memória e identidade social. Estudos Históricos, Rio de Janeiro, FGV, v. 5, n. 10, p. 200-212,1992.

. Memória, esquecimento, silêncio. Estudos Hhstóricos, Rio de Janeiro, v. 2, n. 3, p. 3-15, 1989.

RIBEIRO, Ana Paula Goulart; BARBOSA, Marialva. Memória, relatos autobiográficos e identidade institucional. Comunicação \& Sociedade, n. 47, p. 99-114, 2007.

SANTA CRUZ, Lucia. Desfazendo a mala: memórias de imigrantes na mídia. Contracampo, Universidade Federal Fluminense, v. 17, p. 179-192, 2007.

Experiência de pertencer: o resgate da memória como construção de identidade corporativa. In: CONGRESSO INTERNACIONAL EM COMUNICAÇÃO E CONSUMO - COMUNICON, 2º, São Paulo, 15-16 de outubro de 2012. Anais... São Paulo: ESPM, 2012. 
Cristalizações em comunidades imaginadas: examinando a implantação de um Centro de Documentação e Memória. In: ENCONTRO DE GTs - COMUNICON, 3², São Paulo, 10-11 de outubro de 2013. Trabalho apresentado no Grupo de Trabalho Comunicação, Consumo e Memória. Anais... São Paulo: ESPM, 2013a.

Relatório final de pesquisa estado da arte dos estudos de memória organizacional e comunicação organizacional. 127 f. Rio de Janeiro: ESPM, 2013b.

TOTINI, Maria Elizabeth. A memória como instrumento de gestão empresarial. São Paulo: Aberje, [s.d.]. Disponível em: <http://www.Aberje.com.br/novo/acoes_artigos_mais.asp?id=32>.Acesso em: 11 maio 2012.

Artigo recebido em 02.03.2014 e aprovado em 27.05.2014. 